\title{
Juvenile Pleomorphic Adenoma of the Cheek - A rare case with review of literature
}

\author{
Gupta MK ${ }^{1}$, Bailoor D. N. ${ }^{2}$, Mhaske S. ${ }^{3}$, Raghuvanshi V. ${ }^{4}$, Nahar S. ${ }^{5}$, \\ Raju Ragavendra T. \\ 1. Professor \& Head of Oral Maxillofacial Surgery, and Dean PDA, University, Bhanpur, Bhopal, India \\ 2. Professor \& Head of Oral Medicine and Radiology PDA, University, Bhanpur, Bhopal, India \\ 3. Head of Oral and Maxillofacial pathology PDA, University, Bhanpur, Bhopal, India \\ 4. Post graduate Student, Oral Medicine and Radiology, PDA, University, Bhanpur, Bhopal, India \\ 5. Postgraduate Student Oral Maxillofacial Surgery, PDA, University, Bhanpur, Bhopal, India \\ ${ }^{6 .}$ Reader, Oral and Maxillofacial pathology PDA, University, Bhanpur, Bhopal, India
}

\begin{abstract}
$\overline{\text { ABSTRACT : Pleomorphic adenoma in adolescence is relatively rare. In buccal pad fat area these tumors are }}$ even rarer. A case of Pleomorphic adenoma of buccal pad area of 5 yrs duration, painless \& slow growing is reported. The mass was removed by wide local excision \& a follow up period of $1 \mathrm{yr}$ with no recurrence has been noted. Pleomorphic adenoma should be considered in differential diagnosis of mass of the cheek in youngsters.
\end{abstract}

Keywords: Juvenile, Pleomorphic, Adenoma, Salivary, tumors

\section{Introduction}

Pleomorphic adenoma is a benign salivary gland neoplasm that represents less than $5 \%$ of benign tumors in childhood. ${ }^{1}$ Palate is considered the most common area followed by upper lip \& cheek. ${ }^{2}$ The salivary neoplasm found in most commonly in juveniles is pleomorphic adenoma. Haemangioma and lymphangioma are the mesenchymal tumors which are seen in prevalence after this tumor. ${ }^{1}$ Mucosa of cheek and buccal pad area are uncommon sites for intraoral pleomorphic adenoma. ${ }^{3}$ In children recently only 3 cases have been reported. Here we discuss a case of pleomorphic adenoma in $15 \mathrm{yr}$ old girl and relevant studies are discussed. ${ }^{4,5,6}$

\section{Case report}

A 15 yrs old female patient reported to the department of oral medicine and radiology of our dental college with chief complaint of swelling on left cheek of five years duration. Patient noticed swelling 5 yrs back since then swelling was growing gradually in size, it was asymptomatic with no history of discharge,bleeding, pain, or any sensory changes. Patient had a history of fall 7 yrs back. Her past medical \& dental history was noncontributory.On General examination she had normal gait and countenance, her BMI was 19.4
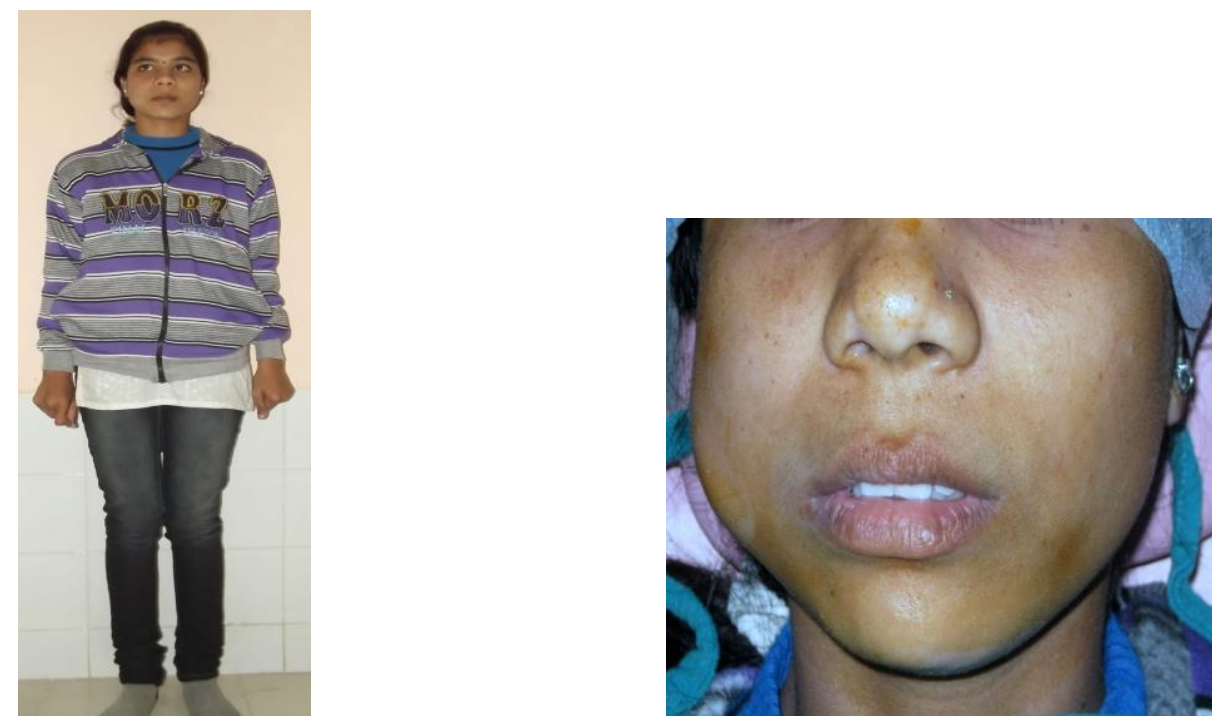

Figure No. 1 : Showing the general examination of the patient with BMI of 19.4 and Extra-oral examination showing the asymmetry due to the buccal swelling approximately 3 X $2 \mathrm{cms}$. 
On Extra Oral examination facial asymmetry due to swelling was noted on the right side. A solitary dome shaped, oval, swelling with smooth surface was present on right cheek region. (Please see figure No. 1) No abnormality detected with overlying skin. Swelling was approximately in mid cheek region $3 \mathrm{X} 2 \mathrm{~cm}$ in size extending superior-inferiorly from ala-tragus line to $2 \mathrm{~cm}$ above the lower border of mandible. Anteroposteriorly its was extending $2 \mathrm{cms}$ from angle of mouth to an perpendicular dropping down from outer canthus of right eye to lower border of mandible .

On palpation inspectory findings were confirmed, additional findings noted were swelling was non tender, firm, non fluctuant, non reducible, non pulsatile \& mobile in all planes. Local temperature over the swelling was not raised. Skin overlying the swelling was pinchable.

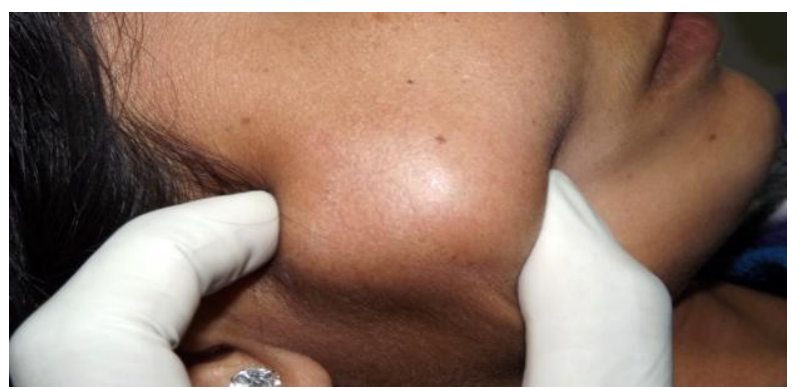

Figure No 2: The swelling was non pulsatile, firm in feel and moving freely in all planes.
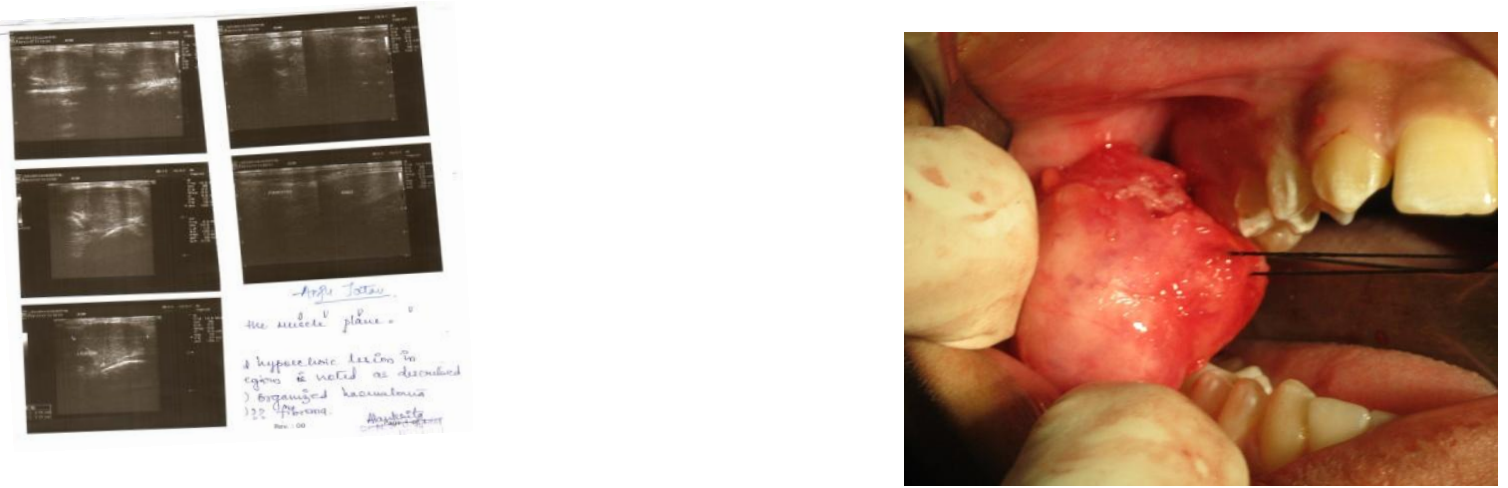

Figure No 3: The Ultrasound report showing well defined hypo- echoic lesion anterior to the muscle plane.

Figure No 4: An excision of the lesion in progress, it was localized easily and had a fibrous capsule.

On the basis of history given by the patient and clinical features a provisional diagnosis of organized hematoma was made; differentials considered were fibroma, antibioma, lipoma, fibrous hyperplasia (reactive to trauma) schwannoma \& pleomorphc adenoma. Investigations advised were panoramic radiograph \& ultra sonography. No abnormality was detected with OPG. USG revealed a well defined, hypoechoic lesion measuring 2.7 X $2.1 \mathrm{~cm}$ was present anterior to the muscle plane. No internal vascularity was noted, no bony involvement was seen.

Excision biopsy was advised as an investigation and treatment plan. Surgical excision was uneventful, excised tissue was sent for pathological examination. Macroscopically tissue was, round to oval in shape, measuring about $2 \times 2 \mathrm{~cm}$, grayish pink in color, soft to firm in consistency; when cut into two halves the cut surface was smooth, covered by well defined thin capsule. The cut surface was uniformly creamy white in color showing a cut potato like surface.

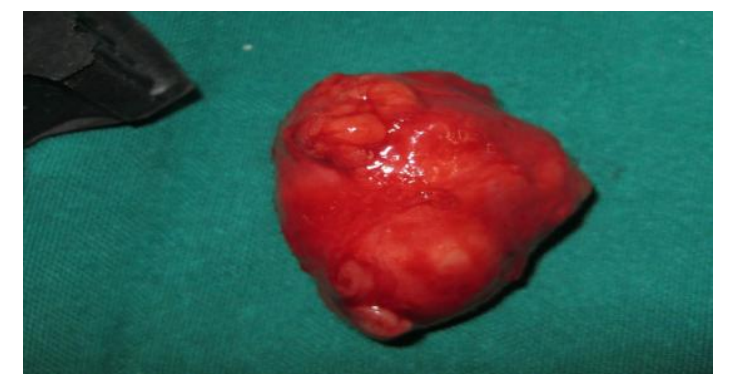

Figure No 5: Showing the gross specimen which was submitted to Oral Pathology department for HP examination. 
Histopathological examination revealed a well defined capsulated tumor mass with combination of epithelial \& stromal components (fig 6). The epithelial constituent was arranged in large sheets \& islands composed of squamous, basaloid \& cuboidal cells, few mucous cells, plenty of plasmacytoid spindle myoepithelial cells and few duct like areas with cuboidal large cells were noted. Areas of chondroid, myxoid, osteoid, were tissue also present with variable predominance (fig,7). The findings were confirmative for the diagnosis of pleomorphic adenoma

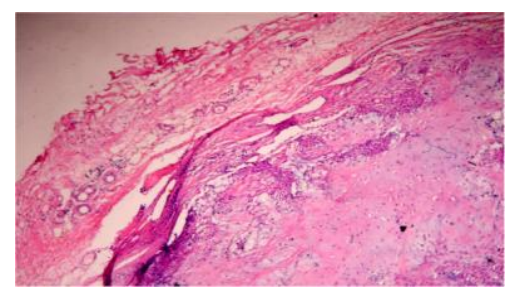

Fig 6 - The tumor was showing a well defined overlying capsule with neoplastic tissue composed of epithelial and variability in stromal components. (low power view).

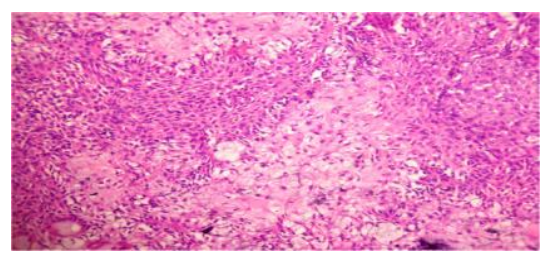

Fig 7 - Epithelial proliferation was in the form of sheets and islands and background stroma was composed of myxoid, chondroid and osseous tissue (high power view).

\section{Discussion}

The mean age at initial presentation of 42 patients treated by Peter Zbären et $\mathrm{al}^{7}$ mentioned that age of recurrence observed was 34 yrs and the interval between initial surgery and tumor recurrence varied between 3 $15 y r s .{ }^{8,9}$ The surgical treatment of pleomorphic adenoma has never been standardized and Renehan A et al 1996 \& Piorkowski RJ et al 1981 both suggested that enucleation is likely to result in recurrence as compared with total gland excision. ${ }^{10,11}$

In our juvenile patient since the surgery was simple and able to completely remove a well circumscribed lesion, the removal of associated gland was not an issue. This is in agreement with Leverstein $\mathrm{H}$ et al 1997 who stated that surgery of this neoplasm must be highly customized on the basis of histologic type, extension \& patients age. ${ }^{12}$

Damage to the peripheral branches of facial nerve is always a surgical risk, when surgical intervention is done ${ }^{3}$ in the facial region. However in this case there was no neurological deficit. This was mainly due to the intraoral approach for the well circumscribed tumor.Response to Radio therapy:

Renehan A et al has suggested adjuvant radiotherapy for Pleomorphic multi nodular recurrent case.$^{10}$ On the contrary Glas AS et al 2001 have stated that only when surgery is contraindicated for medical reasons should radiotherapy be even considered. ${ }^{13}$ Samson MJ et al 1991have suggested that radiation may be justified if surgical risk of sacrificing the adjunct nerve is relatively high. ${ }^{14}$ In our case no such risk was evident and we are prognosticating a low level of recurrence in this well circumscribed \& completely excised tumor.

The differential diagnosis of adolescent Pleomorphic adenoma includes abscess, foreign body reaction to substances like fish bone, fibroma, dermoid cyst, lipoma, \& rare entities like rhabdo-mayo-sarcoma, mucoepidermoid carcinoma \& adenoid cystic carcinoma. ${ }^{15}$.Manjunatha BS et al ${ }^{16}$ have mentioned about a rare variant termed as Fibrolipoma which is seen in the buccal fat region of the face. Early diagnosis of such lesions in Juveniles is very critical.

\section{Conclusion}

To conclude, adolescent Pleomorphic adenoma of cheek is a rare neoplasm and not easily diagnosed at provisional level, wide surgical excision is the treatment of choice and regular follow up at least monthly for period of 24 months would give us a hint of recurrence when it occurs. In India a rare conversion of Pleomorphic adenoma to carcinoma has been reported by Kini Y et al ${ }^{17}$ and this makes the early diagnosis of such seemingly benign lesions even more urgent. 


\section{References}

[1]. Rogerson KC: Salivary gland pathology in children.Oral Maxillofac Surg Clin N Am 7: 591-598, 1995

[2]. Toida M, Shimokawa K, Makita H, Kato K, Kobayashi A, Kusunoki Y, Hatakeyama D, Fujitsuka H, Yamashita T, Shibata T: Intraoral minor salivary gland tumors: a clinicopathological study of 82 cases. Int J Oral Maxillofac Surg 2005, 34:528-32.

[3]. Bablani D, Bansal S, Shetty SJ, Desai R, Kulkarni SR, Prasad P, Karjodkar FR: Pleomorphic adenoma of the cheek: a case report and review. J Oral Maxillofac Surg 2009, 67:1539-42.

[4]. Yamamoto H, Fukumoto M, Yamaguchi F, Sakata K, Oikawa T: Pleomorphic adenoma of the buccal gland in a child. Int $J$ Oral Maxillofac Surg 1986, 15:474-7.

[5]. Cohen MA: Pleomorphic adenoma of the cheek. Int J Oral Maxillofac Surg 1986, 15:777-9.

[6]. Kronenberg J, Horowitz A, Creter D: Pleomorphic adenoma arising in accessory salivary tissue with constriction of Stensen's duct. $J$ Laryngol Otol 1988, 102:382-3.

[7]. Zbären P, Tschumi I, Nuyens M, Stauffer E. Recurrent pleomorphic adenoma of the parotid gland. Am J Surg. 2005 Feb; 189(2):203-

[8]. Naeim F, Forsberg MI, Waisman J, et al. Mixed tumors of the salivary glands. Growth pattern and recurrence. Arch Pathol Lab Med 1976;100:271-5.

[9]. Yugueros P, Goellner JR, Petty PM, et al. Treating recurrence of parotid benign pleomorphic adenomas. Ann Plast Surg 1998;40:573-6.

[10]. Sistrunk WE. Mixed tumours of the parotid gland. Minn Med 1921; 4:155-60

[11]. Klopp CT, Winship T. Treatment of mixed tumors of the parotid gland by subtotal parotidectomy. Arch Surg 1950;61:477-86.

[12]. Leverstein H, Tiwari RM, Snow GB, et al. The surgical management of recurrent or residual pleomorphic adenomas of the parotid gland. Analysis and results in 40 patients. Eur Arch Otorhinolaryngol 1997; 254:313-7.

[13]. Glas AS, Vermey A, Hollema H, et al. Surgical treatment of recurrent pleomorphic adenoma of the parotid gland: a clinical analysis of 52 patients. Head Neck 2001;23:311-6.

[14]. Samson MJ, Metson R, Wang CC, et al. Preservation of the facial nerve in the management of recurrent pleomorphic adenoma. Laryngoscope 1991;101:1060-2.

[15]. Baldus SE, Streppel M, Stennert E, Dienes HP: Pleomorphic adenoma (mixed tumor) of the external auditory canal. Differential diagnosis of the tumors of the ceruminal glands. Pathologe 1999, 20:125-9.

[16]. B.S. Manjunatha,1 G.S. Deepak Pateel,2 and V. Shah3. Oral Fibrolipoma-A Rare Histological Entity: Report of 3 Cases and Review of Literature J Dent (Tehran). 2010 Autumn; 7(4): 226-231.

[17]. Kini Y, Desai C, Mahindra U, Kalburge J. Rare carcinoma ex pleomorphic adenoma of the buccal minor salivary gland causing a therapeutic dilemma. Contemp Clin Dent. 2012 Apr;3(2):209-11 